\title{
Leprosy Mimicking as Rheumatoid Arthritis: A Case Report
}

\author{
Made Edwin Sridana ${ }^{1 *}$ (D), Pande Ketut Kurniari ${ }^{2}$, Gede Kambayana ${ }^{2}$ \\ ${ }^{1}$ Internal Medicine Residency Program, Faculty of Medicine, Universitas Udayana, Bali, Indonesia; ${ }^{2}$ Department of Internal \\ Medicine, Rheumatology Division, Faculty of Medicine, Universitas Udayana, Bali, Indonesia
}

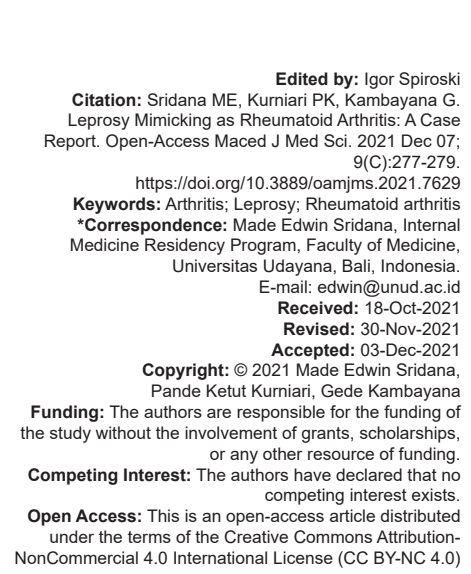

Introduction

Leprosy is a chronic granulomatous infection caused by Mycobacterium leprae, primarily involving the skin and peripheral nerves, musculoskeletal. The clinical manifestations vary and are called "the great imitator" [1], [2]. The WHO reported global prevalence of leprosy at the end of 2012 was 189,018 cases from 115 countries, while the incidence in Indonesia in 2017 was 15,920 [3].

Rheumatological clinical features are often poorly recognized, with musculoskeletal involvement as the third most common. Manifestation forms in acute symmetric polyarthritis or swollen hand and foot during leprosy reactions, Charcot's arthropathy, and symmetrical chronic polyarthritis resembling rheumatoid arthritis (RA) and tenosynovitis. Joint involvement presents as an isolated feature even without involving skin lesions [4], [5]. A study in Brazil stated that arthritis leprosy was found in $6.3 \%$ of patients. Leprosy arthritis is frequently underdiagnosed and rarely recognized by clinicians. Delay diagnosis and management lead to deformity and loss of joint function. The report aims to enhance clinical awareness to recognize this case.

\section{Case Illustration}

A 20-year-old Balinese male presented to the emergency department with subfebrile, erythema rash on thorax after sun exposed, fatigue, and multiple joint pain and swelling preceded by 8 weeks, worse 3 days, and has the previous erythema macula and nodular skin lesion over the face, all four limbs, and upper chest symmetrically. Small joints of hands, bilateral elbows, knees, and feet were painful.

The patient had a history of the same complaints. On examination, the patient was febrile with a temperature of $36.8^{\circ} \mathrm{C}$, blood pressure of $110 / 80$, pulse $90 / \mathrm{min}$, and visual analog scale $4 / 10$. His general appearance revealed multiple painful nodular skin lesions over the face, thoracoabdominal, upper, and lower limbs (Figure 1). There was a sharp margin, round-geographic shape, with $2-4 \mathrm{~cm}$ of diameter, distributed bilaterally and near symmetric.

Neurological examination showed decreased sensation over plantar right and left, motoric intact, at dorsum manus and right and left pedal, and decreased sensibility. Monofilament assessment found a purple indicator with a value of $2.0 \mathrm{gf}$ on 


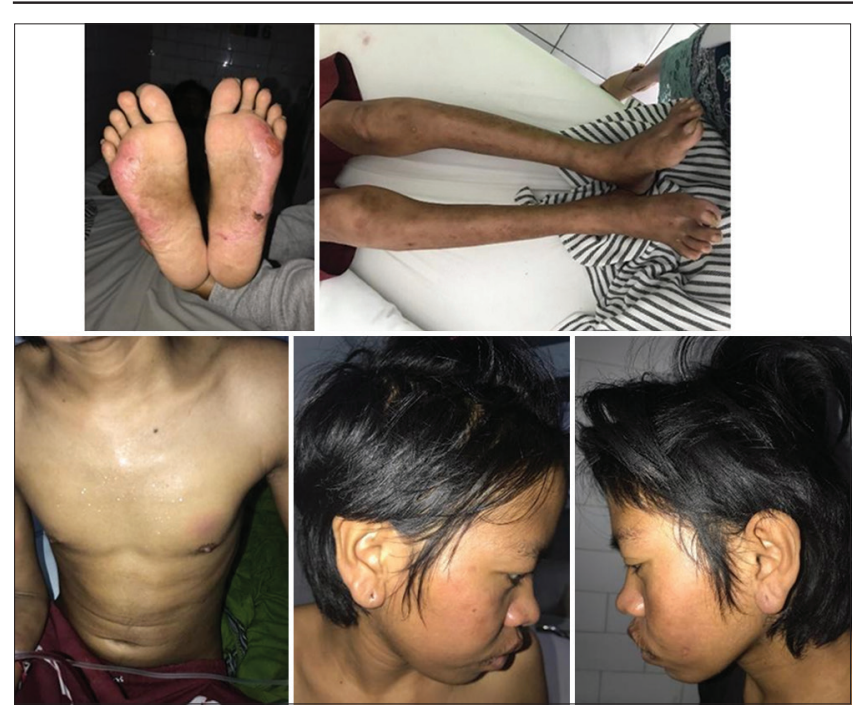

Figure 1: Nodular skin lesions over the face and ear

manus, while pedis dark red color with a $4.0 \mathrm{gf}$. The voluntary muscle test was normal. Peripheral nerve examination showed thickened posterior right auricle. Musculoskeletal examination revealed tender and swollen bilateral metacarpophalangeal, pain on palpation, limited flexion, and joint extension on proximal interphalangeal.

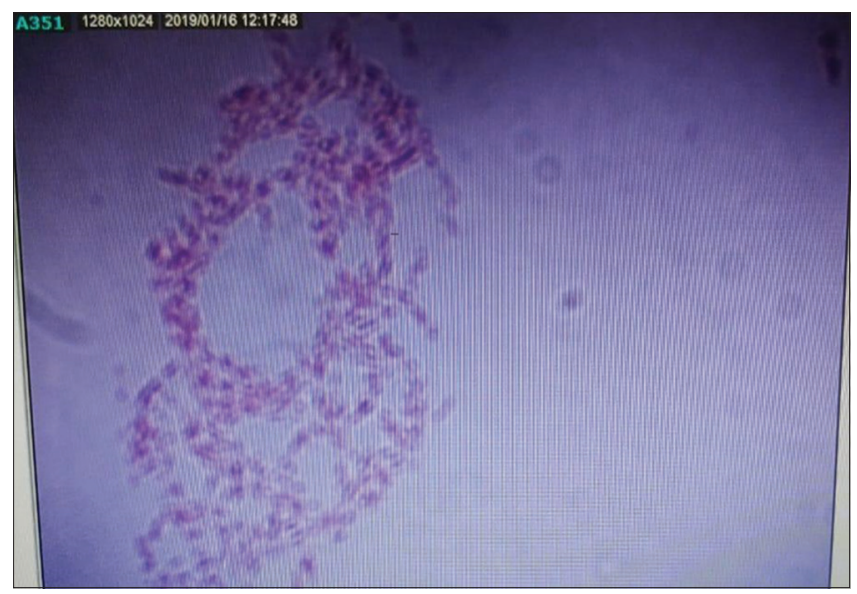

Figure 2: Histopathology of a skin nodule

Laboratory investigations revealed leukocytosis $14.22 \times 10^{3} / \mu \mathrm{L}$, dominance by neutrophils, hemoglobin of $7.68 \mathrm{~g} / \mathrm{dL}$, and inflammatory markers were raised (C-reactive protein of $62.46 \mathrm{mg} / \mathrm{L}$ ). Liver, renal function, and urine chemical examination were normal. Further investigation found that rheumatoid factor (RF) was negative.

Ziehl-Neelsen staining on the lesion in the right ear lobe was found 10-20 cells/visual field, granular $(+4)$ and 15-20 cells/visual field on the left earlobe, granular (+4) (Figure 2).

Treatment of this case included an initial approach and anti-leprosy medication. The patient was given hydration and diclofenac sodium $50 \mathrm{mg}$ every $12 \mathrm{~h}$ as anti-pain and blood transfusions, while for leprosy treatment, that is, rifampicin $600 \mathrm{mg}$ and clofazimine $300 \mathrm{mg}$ monthly and dapsone $100 \mathrm{mg}$, with methylprednisolone $16 \mathrm{mg}$ orally every $8 \mathrm{~h}$ and Vitamin B complex (B1, B6, and B12) single tablet every day. The complaints were resolved 7 days after starting treatment with multidrug anti-leprosy medication.

\section{Discussion}

Musculoskeletal features are common in leprosy but infrequently reported. Joint involvement occurs in more than half of cases of leprosy in several forms of monoarticular, oligoarticular, or polyarticular. The mechanism is unknown and related to direct bacterial infiltration of the synovium of leprosy reaction (Type I or Type II) [6], [7]. Joint involvement caused by leprosy is divided into four categories: Charcot's arthropathy secondary to peripheral sensory neuropathy; swollen hands and feet syndrome; acute polyarthritis of lepra reaction; and chronic arthritis from direct infiltration of the synovium by lepra bacilli [5].

The clinical features with a classic skin lesion with acute polyarthritis led to the diagnosis of leprosy. Clinical presentation mimics RA or systemic lupus erythema (SLE), leprosy lesions classical affect the peripheral nerves, particularly the posterior tibial, ulnar, median, and peroneus common nerve, such as numb skin lesions and thickening nerves, and nerve pain enhances leprosy [8], [9]. Sometimes, it is difficult to differentiate symmetrical polyarthritis due to leprosy from RA as in our patient. The detection of the low levels of autoantibodies such as RF, antinuclear antibody, anti-cyclic citrullinated peptide, and anti-neutrophil cytoplasmic antibody has been reported in recent studies in leprosy patients and may be an issue [2], [10], [11]. The absence of RF and extra-articular rheumatoid features, male, responsiveness to anti-leprosy treatment, was a clinical differentiator from RA in our patient. The manifestation of skin lesions in borderline type leprosy mimics skin lesions in SLE or RA and is challenging to differentiate diagnosis among those [11], [12].

Our patient's presentation with nodule skin lesion combined with acute polyarthritis leads to a diagnosis of leprosy. The patient was managed as leprosy and responded well. Most cases of leprosyrelated arthritis are associated with reactional episodes, and, in many patients, arthritis evolves chronically and does not respond to conventional therapy for reaction. In this case, it was diagnosed as a new case of borderline lepromatous (BL) type.

Type BL leprosy is a progressive disease, characterized by nerve injury and various complications such as deformity, peripheral neuropathy, lagophthalmos, keratitis, and pedis ulcers [13]. Peripheral neuropathy occurs in $20 \%$ of leprosy patients during the 1 year of treatment. This peripheral neuropathy manifests as paresthesia and tingling in 
the stocking and glove pattern sensation (S-GPSI). Symptoms initially involve the lower extremities and then the upper extremities [13], [14], [15]. In this case, the patient presents S-GPSI with complaints of tingling started from both hands then the feet. This complication was characterized by the decreased sensibility of touch, pain, and temperature on both the dorsum and plantar manus and pedis, and sensory examination with monofilament was found to have decreased (both dorsum and plantar manus were purple with a value of $2.0 \mathrm{gf}$ and both dorsum and plantar pedis are dark red with a value of $4.0 \mathrm{gf}$ ).

Management of arthritis includes giving diclofenac sodium as pain treatment; however, the main principle is to overcome the underlying process, which is leprosy, by giving multidrug therapy.

The prognosis of leprosy varies depending on the severity of the disease at the time of diagnosis and therapy and the presence or absence of complications, such as reactions and deformities, in the patient. This emphasizes the need for early diagnosis and treatment helps prevent further damage and complications [15].

\section{Conclusion}

The clinical features of a classic skin lesion with acute polyarthritis lead to the diagnosis of leprosy. The question was raised about differentiating between SLE and RA and being challenging in diagnosis and enhancing clinical awareness to recognize.

\section{References}

1. Horta-Baas G, Hernández-Cabrera MF, Barile-Fabris LA, del S Romero-Figueroa M, Arenas-Guzmán R. Multibacillary leprosy mimicking systemic lupus erythematosus: Case report and literature review. Lupus. 2015;24(10):1095-102. https://doi. org/10.1177/0961203315574557

PMid:25761657

2. Gao LN, Zhong B, Wang Y. Rheumatoid arthritis-like features in Hansen disease: A case report. Medicine. 2018;97(29):e11590. https://doi.org/10.1097/MD.0000000000011590

PMid:30024562
3. Alam F, Al Emadi S. Case of arthritis secondary to leprosy. SpringerPlus. 2014;3:734. https://doi. org/10.1186/2193-1801-3-734

PMid:26034700

4. Conceição R, Penna ML. Leprosy: Current situation, clinica and laboratory aspects, treatment history and perspective of the uniform multidrug therapy for all patients. An Bras Dermatol. 2017;92(6):761-73. https://doi.org/10.1590/ abd1806-4841.20176724

PMid:29364430

5. Chauhan S, Wakhlu A, Agarwal V. Arthritis in leprosy. Rheumatology (Oxford). 2010;49(12):2237-42. https://doi. org/10.1093/rheumatology/keq264

PMid:20724432

6. Graham A, Furlong S, Margoles LM, Owusu K, Franco-Paredes C. Clinical management of leprosy reactions. Infect Dis Clin Pract. 2010;18(4):235-8. https://doi.org/10.1097/ IPC.0b013e3181deba2a

7. Bhat RM, Prakash C. Leprosy: An overview of pathophysiology. Interdiscip Perspect Infect Dis. 2012;2012:181089. https://doi. org/10.1155/2012/181089 PMid:22988457

8. Nascimento OJ. Leprosy neuropathy: Clinical presentations Arq Neuropsiquiatr. 2013;71(9):661-6. https://doi. org/10.1590/0004-282X20130146

PMid:24141500

9. Rita $T$, de Oliveira M. Arthritis and diagnosis of leprosy: A case report and review of the literature. An Bras Dermatol. 2014;89(2):323-5. https://doi.org/10.1590/ abd1806-4841.20142857

PMid:24770512

10. Wakhlu A, Sawlani K, Himanshu D. Rheumatological manifestations of hansen's disease. Indian $\mathrm{J}$ Rheumatol. 2018;13(1):14-9. https://doi.org/10.4103/injr.injr_52_17.

11. Zavala-Cerna MG, Fafutis-Morris M, Guillen-Vargas $C$, Salazar-Páramo M, García-Cruz DE, Riebeling C, et al. Anticyclic citrullinated peptide antibodies and rheumatoid factor sera titers in leprosy patients from Mexico. Rheumatol Int. 2012;32(11):3531-6. https://doi.org/10.1007/s00296-011-2224-0 PMid:22083616

12. Katulanda P, Dilrukshi MD, Ratnasamy V. Remission strategy in type 2 diabetes mellitus - a paradigm shift in the management of newly diagnosed patients. Sri Lanka J Diabetes Endocrinol Metab. 2019;9(1):33. https://doi.org/10.4038/sjdem.v9i1.7373

13. Kang S. Fitzpatrick's Dermatology. $9^{\text {th }}$ ed. United States: McGraw-Hill Education; 2019.

14. Jerajani HR. IAL Textbook of leprosy-hemanta Kumar Kar and Bhushan Kumar. Indian J Dermatol Venereol Leprol. 2010;76:309-10.

15. Reibel F, Cambau E, Aubry A. Update on the epidemiology, diagnosis, and treatment of leprosy. Med Malad Infect. 2015;45(9):383-93. https://doi.org/10.1016/j. medmal.2015.09.002

PMid:26428602 